Supplement of

\title{
Measurement-based climatology of aerosol direct radiative effect, its sensitivities, and uncertainties from a background southeast US site
}

\section{James P. Sherman and Allison McComiskey}

Correspondence to: James P. Sherman (shermanjp@appstate.edu)

The copyright of individual parts of the supplement might differ from the CC BY 3.0 License. 


\section{Supplemental Materials}

\section{Overview}

The following materials supplement the manuscript "Measurement-based climatology of aerosol direct radiative effect, its sensitivities, and uncertainties from a background southeastern US site”. We first apply techniques identical to those described in Sects. 4.3 and 4.4 for calculating sensitivities and measurement uncertainties in the aerosol direct radiative effect (DRE) to calculate the sensitivities and uncertainties in aerosol radiative efficiency (RE; equal to the DRE per unit aerosol optical depth) at $550 \mathrm{~nm}$ (Sects. S1 and S2). We then evaluate the sensitivity of DRE to surface types (Sect. S3), which facilitates comparisons with other studies in Sect. 5.2 of the paper.

\section{S1. Sensitivity of RE to aerosol optical properties and surface reflectance}

The uncertainty $\triangle \mathrm{RE}$ follows an equation identical to Eq. (7) for $\triangle \mathrm{DRE}$

$$
\begin{aligned}
& \Delta R E^{2}=s_{A O D}^{2} \Delta A O D^{2}+s_{\omega_{0}}^{2} \Delta \omega_{0}^{2}+s_{g}^{2} \Delta g^{2}+s_{R}^{2} \Delta R^{2}+2 s_{A O D} s_{\omega_{0}} \operatorname{corr}\left(A O D, \omega_{0}\right) \Delta A O D \cdot \Delta \omega_{0} \\
& +2 s_{A O D} s_{g} \operatorname{corr}(A O D, g) \Delta A O D \cdot \Delta g+2 s_{A O D} s_{R} \operatorname{corr}(A O D, R) \Delta A O D \cdot \Delta R+2 s_{\omega_{0}} s_{g} \operatorname{corr}\left(\omega_{0}, g\right) \Delta \omega_{0} \cdot \Delta g+ \\
& 2 s_{\omega_{0}} s_{R} \operatorname{corr}\left(\omega_{0}, R\right) \Delta \omega_{0} \cdot \Delta R+2 s_{g} s_{R} \operatorname{corr}(g, R) \Delta g \cdot \Delta R
\end{aligned}
$$

We use lower-case ' $\mathrm{s}$ ' for the RE sensitivities, so as not to confuse them with the upper-case 'S' used in the main paper for the DRE sensitivities. We use the same base case aerosol optical properties and surface reflectance (Table 1), measurement uncertainties (Table 2), and correlations amongst aerosol optical properties (Table 3) for calculating the RE sensitivities and uncertainties as for DRE sensitivities (Sect. 5.2) and uncertainties (Sect. 5.3).

Aerosol RE is most sensitive to single-scattering albedo $\left(\omega_{0}\right)$ for all seasons (Table S1) and is least sensitive to aerosol optical depth(AOD). For the most part, sensitivities of RE to scattering asymmetry parameter (g) are comparable and surface reflectance (R). For all seasons except summer, RE is $~ 1.5$ times more sensitive to $\omega_{0}$ than to $g$ at the top-of-atmosphere (TOA) and 2.5 times more sensitive to $\omega_{0}$ than to $g$ at the surface. In summer, RE sensitivity to $\omega_{0}$ is higher than sensitivity to $g$ by a factor of $\sim 2$ at the TOA and $\sim 3$ at the surface. The seasonal variations in $\mathrm{s}_{\omega 0}$, $S_{g}$, and $S_{R}$ (Table S1) are much smaller than those of $S_{\omega 0}, S_{g}$, and $S_{R}$ (Tables 5 and 6), with all varying by a factor of 2 or less with season. The fact that $\mathrm{s}_{\omega 0}, \mathrm{~s}_{\mathrm{g}}$, and $\mathrm{s}_{\mathrm{R}}$ all have the same sign (positive) at the surface (Table S1) is what drives surface RE to such small negative values in the 
summer (Fig.3d of main paper), when $\mathrm{g}, \omega_{0}$, and $\mathrm{R}$ are all highest and to more negative values in winter, when $\mathrm{g}, \omega_{0}$, and $\mathrm{R}$ are all lowest. The larger sensitivity of RE to AOD during DEC and MAR is consistent with the slight departure from linearity of the DRE versus AOD curve during these months (Figs. 5a and 6a). By definition, RE is the DRE per unit AOD so the sensitivity saod is the second derivative of DRE with respect to AOD.

\section{S2. Uncertainties in RE}

As with the uncertainties in DRE (Sect. 5.3), the RE uncertainties at the TOA (Table S2) and surface (Table S3) are largely influenced by the sensitivities (Table S1). The uncertainties in $\omega_{0}$ are the largest contributor to $\triangle \mathrm{RE}$ during all seasons, especially at the surface. Inclusion of covariances amongst aerosol optical properties increases $\triangle \mathrm{RE}$ by $\sim 20-25 \%$ at the TOA and $\sim 10-$ $15 \%$ at the surface, for all seasons. Still, the RE uncertainties are relatively small for all seasons, ranging from $11-17 \%$ of RE computed using base-case properties (Table 1) at the TOA.

\section{S3. Dependence of DRE on AOD and $\omega_{0}$ for different surface types}

Aerosol DRE depends not only on the aerosol optical properties (AOD, $\omega_{0}$, g) but also on the underlying surface, namely its spectral reflectivity. In the main paper, we parameterized the wavelength-dependent surface reflectance by its spectrally-averaged value $R$. We also parameterized it as a linear combination of the spectral reflectance curves produced by the surface types (snow, water, sand, vegetation) used as inputs to the SBDART radiative transfer model. In this section, we plot the dependence of DRE on AOD and $\omega_{0}$ (the two most influential aerosol parameters; Sect. 5.2) for each of the individual surface types. The results will facilitate comparisons with other studies ( Gadhavi and Jayaraman,2004) and help illustrate how the relative albedos of the aerosol and underlying surface impact DRE. 
Table S1. Sensitivity of aerosol radiative efficiency (RE) at the top-of-atmosphere (TOA) and surface to AOD, $\omega_{0}$, g, and R, which are used to calculate the RE uncertainties. Sensitivities $S_{i}=$ $\frac{\partial R E}{\partial \rho_{i}}$ are calculated as the slope of RE versus $\rho_{\mathrm{i}}$, evaluated at base case values (Table 1). All sensitivities are in units of $\mathrm{W} \mathrm{m}^{-2} \mathrm{AOD}^{-1}$ per unit change in the parameter $\rho_{\mathrm{i}}$. The correlations between aerosol optical properties are used along with uncertainties (Table 2) to calculate the covariances used in the RE uncertainty calculations (Tables S2 and S3).

\begin{tabular}{lllll}
\hline Property $\mathrm{p}_{\mathrm{i}}$ & MAR & $\mathrm{JUN}$ & $\mathrm{SEP}$ & DEC \\
\hline TOA $\mathrm{s}_{\mathrm{AOD}}$ & 35.1 & 19.8 & 20.9 & 47.0 \\
TOA $\mathrm{s}_{\omega 0}$ & -182 & -258 & -178 & -132 \\
TOA $\mathrm{s}_{\mathrm{g}}$ & 118 & 121 & 116 & 91.8 \\
TOA $\mathrm{s}_{\mathrm{R}}$ & 158 & 113 & 91 & 102 \\
Surface $\mathrm{s}_{\mathrm{AOD}}$ & 34.8 & 18.9 & 20.8 & 55.6 \\
Surface $\mathrm{s}_{\omega 0}$ & 310 & 357 & 301 & 214 \\
Surface $\mathrm{s}_{\mathrm{g}}$ & 122 & 126 & 120 & 92.8 \\
Surface $\mathrm{s}_{\mathrm{R}}$ & 130 & 93.2 & 76.9 & 89.3 \\
Corr(AOD, $\left.\omega_{0}\right)$ & -0.02 & 0.25 & 0.57 & 0.10 \\
Corr(AOD,g) & -0.08 & 0.30 & 0.56 & 0.15 \\
Corr $\left(\omega_{0}, \mathrm{~g}\right)$ & 0.78 & 0.79 & 0.85 & 0.84 \\
\hline
\end{tabular}

Table S2. Calculated uncertainties in RE at the TOA, using the sensitivities and correlations given in Table S1 and measurement uncertainties given in Table 2 as inputs to Eq.S1. Units of $\triangle \mathrm{RE}$ are $\mathrm{W} \mathrm{m} \mathrm{m}^{-2} \mathrm{AOD}^{-1}$.

\begin{tabular}{lllll}
\hline & $\mathrm{MAR}$ & $\mathrm{JUN}$ & $\mathrm{SEP}$ & $\mathrm{DEC}$ \\
\hline$\Delta \mathrm{RE}_{\mathrm{AOD}}$ & 0.35 & 0.20 & 0.21 & 0.47 \\
$\Delta \mathrm{RE}_{\omega 0}$ & 5.5 & 5.2 & 3.6 & 3.9 \\
$\Delta \mathrm{RE}_{\mathrm{g}}$ & 1.2 & 1.2 & 1.2 & 0.92 \\
$\Delta \mathrm{RE}_{\mathrm{R}}$ & 3.2 & 2.3 & 1.8 & 2.0 \\
Sum of covariance terms & 9.9 & 10 & 8.1 & 6.6 \\
$\Delta \mathrm{RE}$ & 5.6 & 5.3 & 3.8 & 4.1 \\
$\begin{array}{l}\text { (covariance terms not } \\
\text { included) }\end{array}$ & & & \\
$\begin{array}{l}\Delta \mathrm{RE} \\
\text { (covariance terms included) }\end{array}$ & 7.2 & 6.6 & 5.0 & 5.2 \\
$\mathrm{RE}$ (Base case) & -48.6 & -38.1 & -36.4 & -45.8 \\
$\Delta \mathrm{RE}^{\mathrm{a}}$ / RE (Base Case) & 0.15 & 0.17 & 0.14 & 0.12 \\
\hline
\end{tabular}

${ }^{\mathrm{a} U n c e r t a i n t y ~ i n c l u d e s ~ c o v a r i a n c e ~ t e r m s ~}$ 
Table S3. Calculated uncertainties in RE at the surface, using the sensitivities and correlations given in Table $\mathrm{S} 1$ and measurement uncertainties given in Table 2 as inputs to Eq.S1. Units of $\triangle \mathrm{DRE}$ are $\mathrm{W} \mathrm{m}^{-2} \mathrm{AOD}^{-1}$

\begin{tabular}{lllll}
\hline & MAR & JUN & SEP & DEC \\
\hline$\Delta \mathrm{RE}_{\mathrm{AOD}}$ & 0.35 & 0.19 & 0.21 & 0.56 \\
$\Delta \mathrm{RE}_{\omega 0}$ & 9.3 & 7.1 & 6.0 & 6.4 \\
$\Delta \mathrm{RE}_{\mathrm{g}}$ & 1.2 & 1.3 & 1.2 & 0.93 \\
$\Delta \mathrm{RE}_{\mathrm{R}}$ & 2.6 & 1.9 & 1.5 & 1.8 \\
Sum of covariance terms & 17 & 15 & 14 & 11 \\
$\begin{array}{l}\Delta \mathrm{RE} \\
\text { (covariance terms not }\end{array}$ & 9.7 & 7.5 & 6.3 & 6.7 \\
$\begin{array}{l}\text { included) } \\
\begin{array}{l}\mathrm{RE} \\
\text { (covariance terms included) }\end{array}\end{array}$ & 11 & & & \\
$\mathrm{RE}$ (Base case) & & & & \\
$\Delta \mathrm{RE}^{\mathrm{a}} / \mathrm{RE}$ (Base Case) & -91.8 & -72.0 & 7.4 & 7.5 \\
\hline
\end{tabular}

${ }^{\mathrm{a} U n c e r t a i n t y ~ i n c l u d e s ~ c o v a r i a n c e ~ t e r m s ~}$ 
(a)

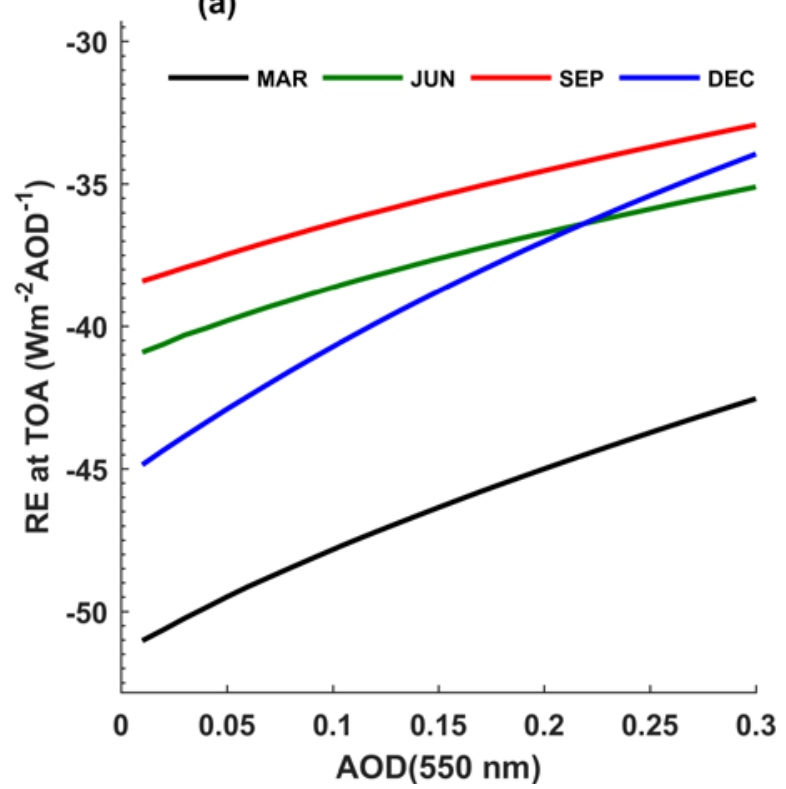

(c)

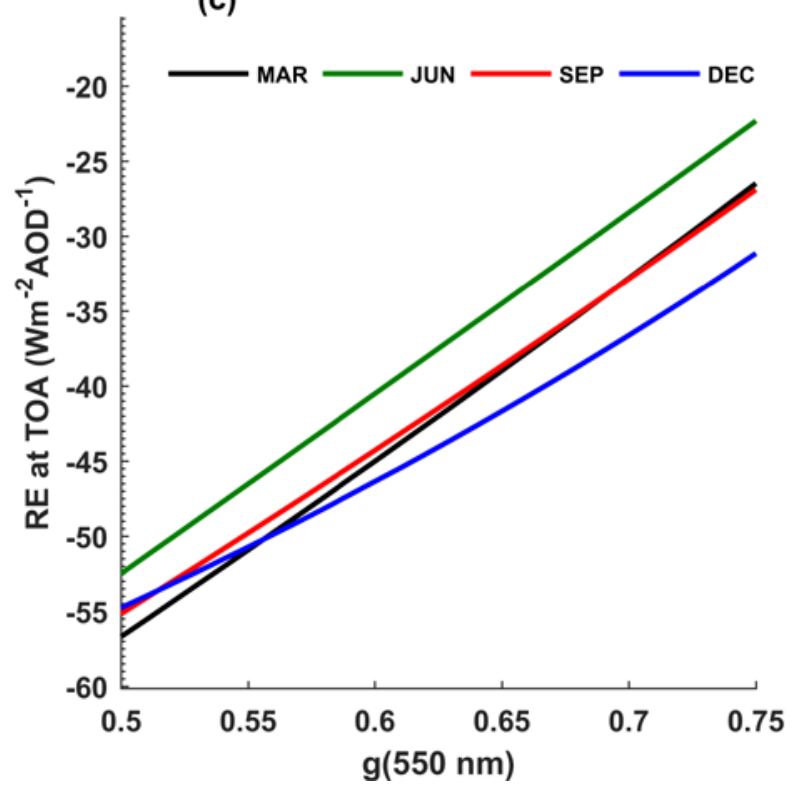

(b)

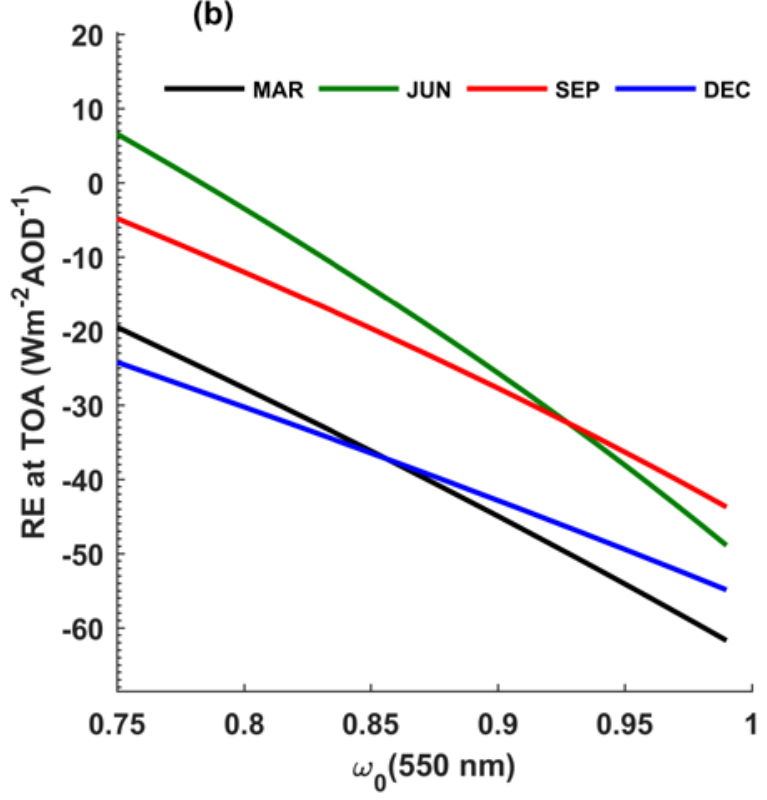

(d)

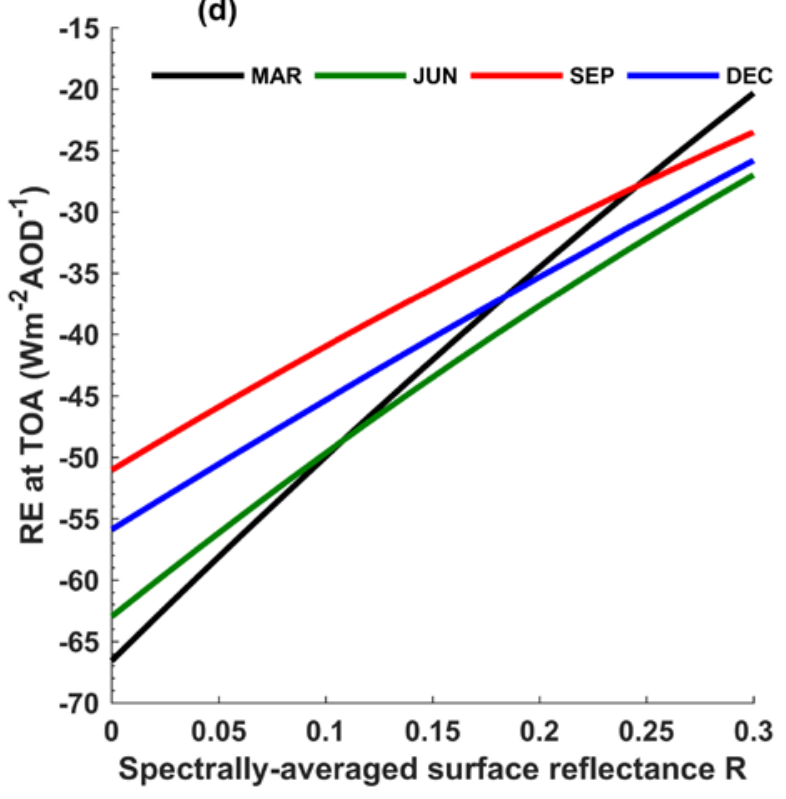

Figure S1. Seasonal dependence of the sensitivity of top-of-atmosphere (TOA) aerosol RE to (a) AOD; (b) $\omega_{0}$; (c) g; and (d) spectrally-averaged surface reflectance $R$ 
(a)

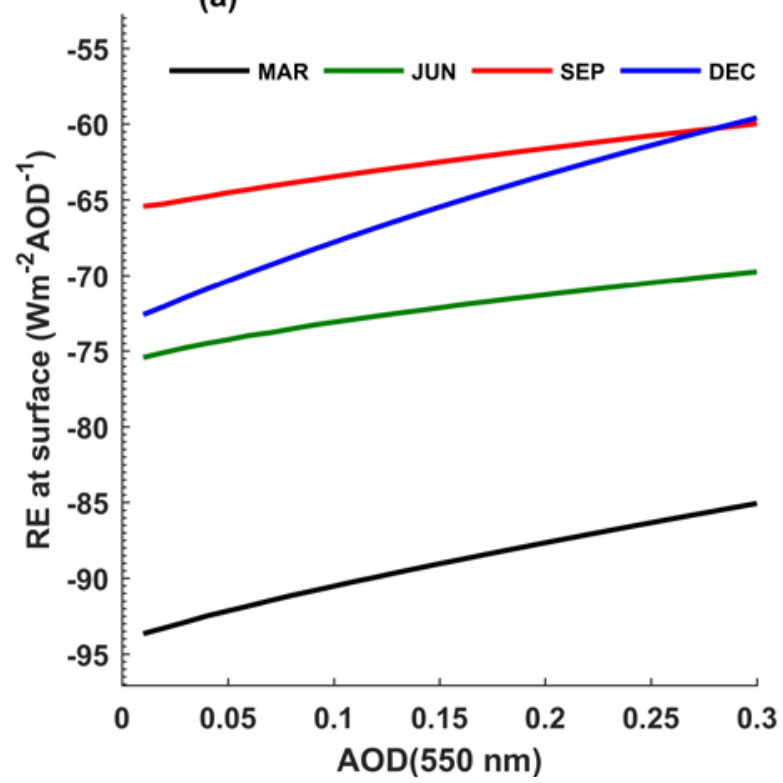

(c)

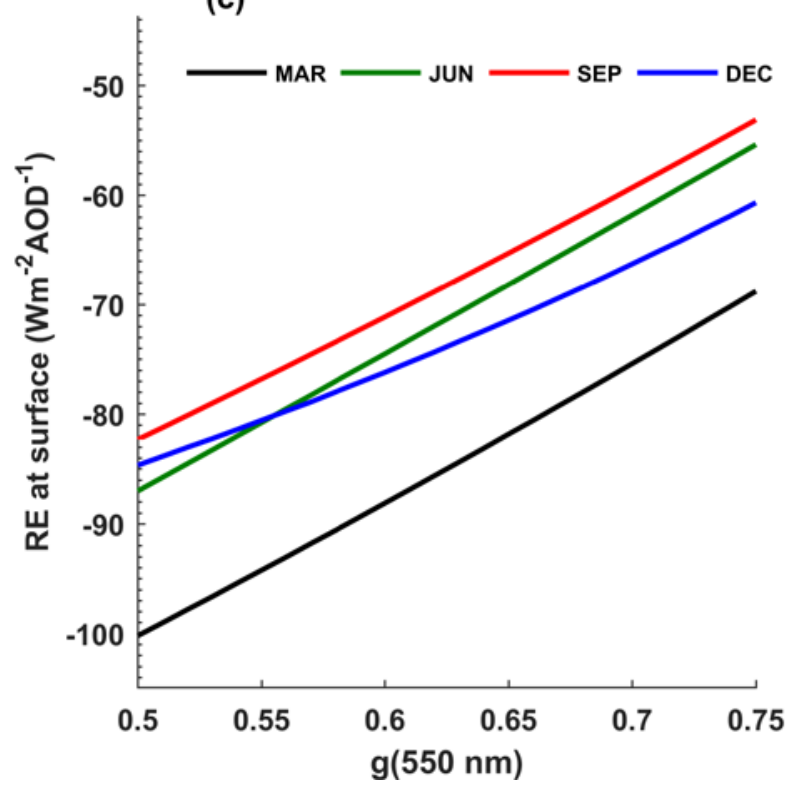

(b)

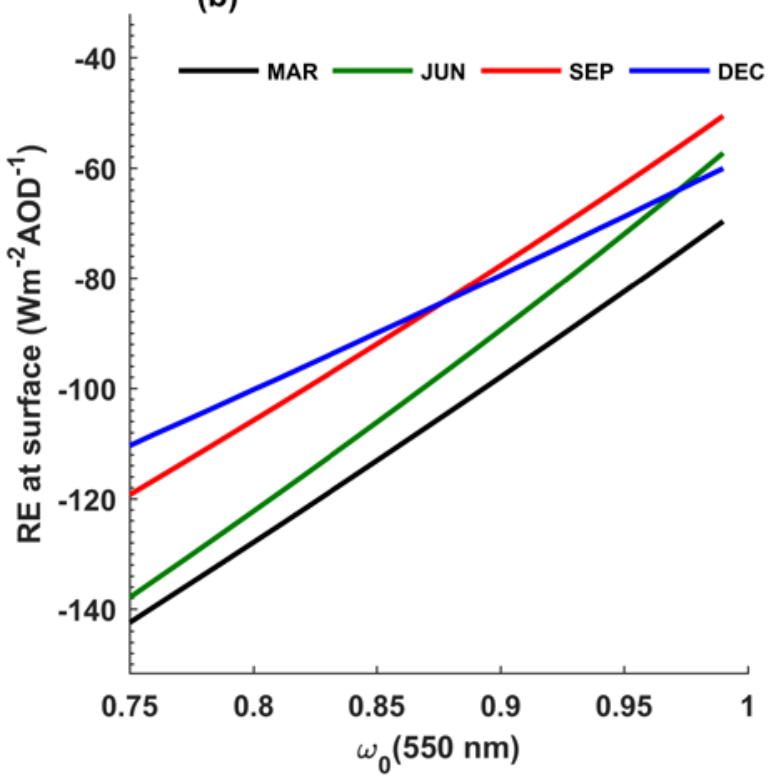

(d)

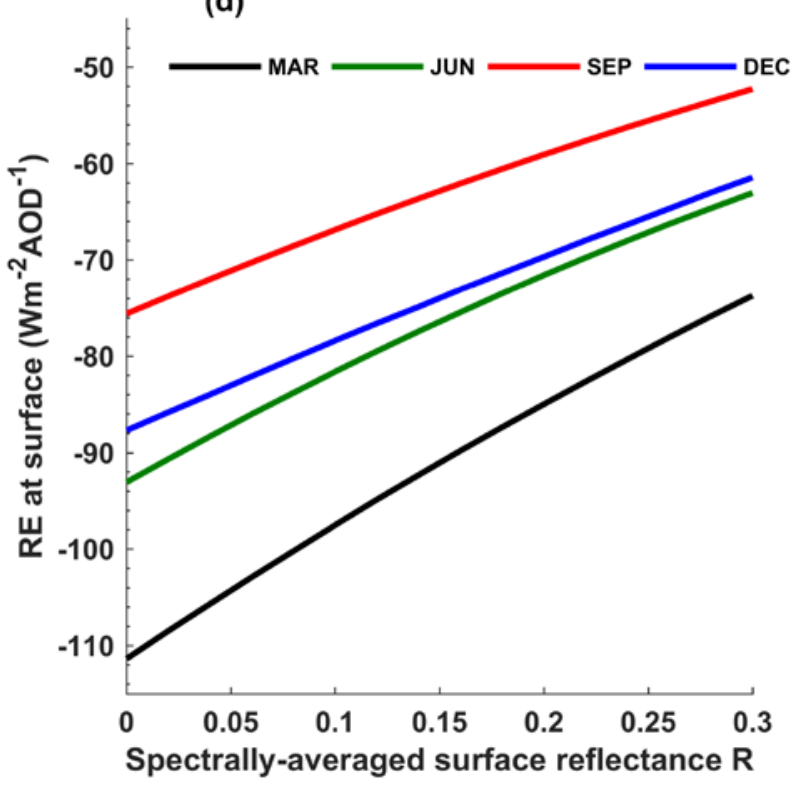

Figure S2. Seasonal dependence of the sensitivity of aerosol RE at the surface to (a) AOD; (b) $\omega_{0}$; (c) g; and (d) spectrally-averaged surface reflectance $R$ 

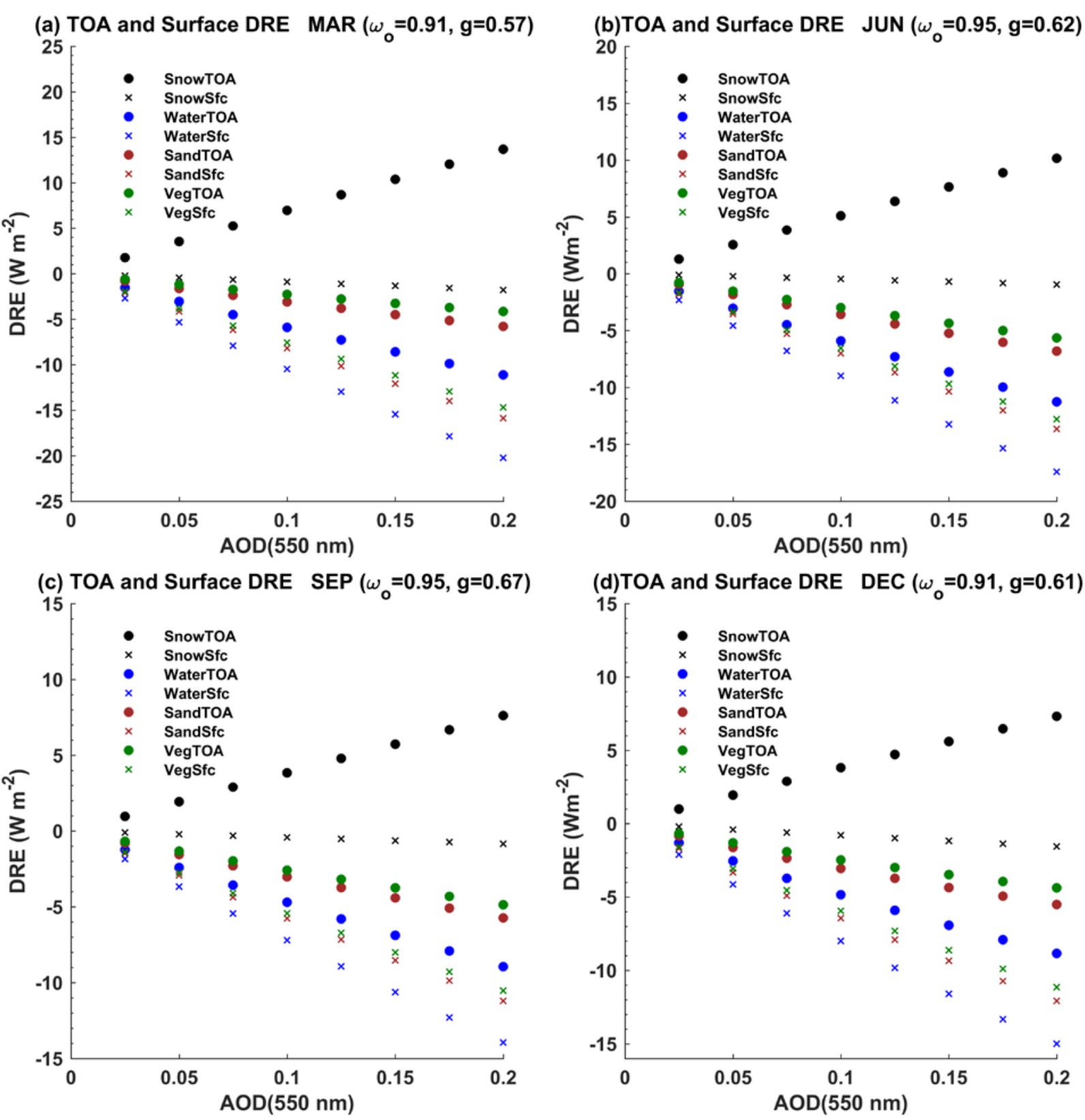

Fig. S3. Sensitivity of DRE at the TOA and surface to changes in AOD for the following surface types: snow, seawater, sand, and vegetation; for MAR, JUN, SEP, and DEC. The base-case value of $\omega_{\mathrm{o}}$ and $\mathrm{g}$ for each season (Table 1 of paper) are included in each plot title. 


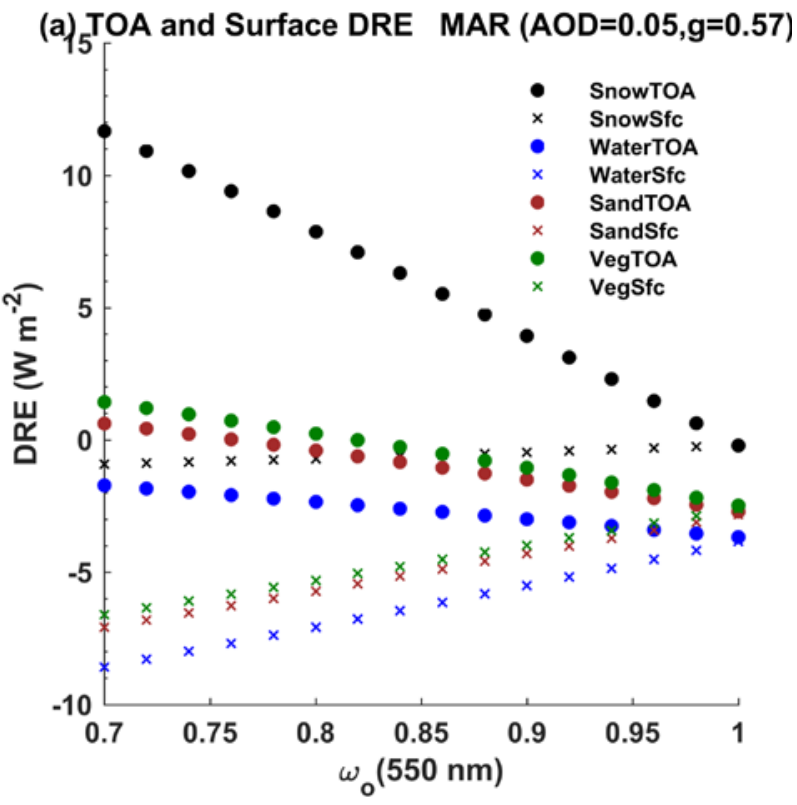

(b)TOA and Surface DRE JUN $(A O D=0.15, g=0.62)$
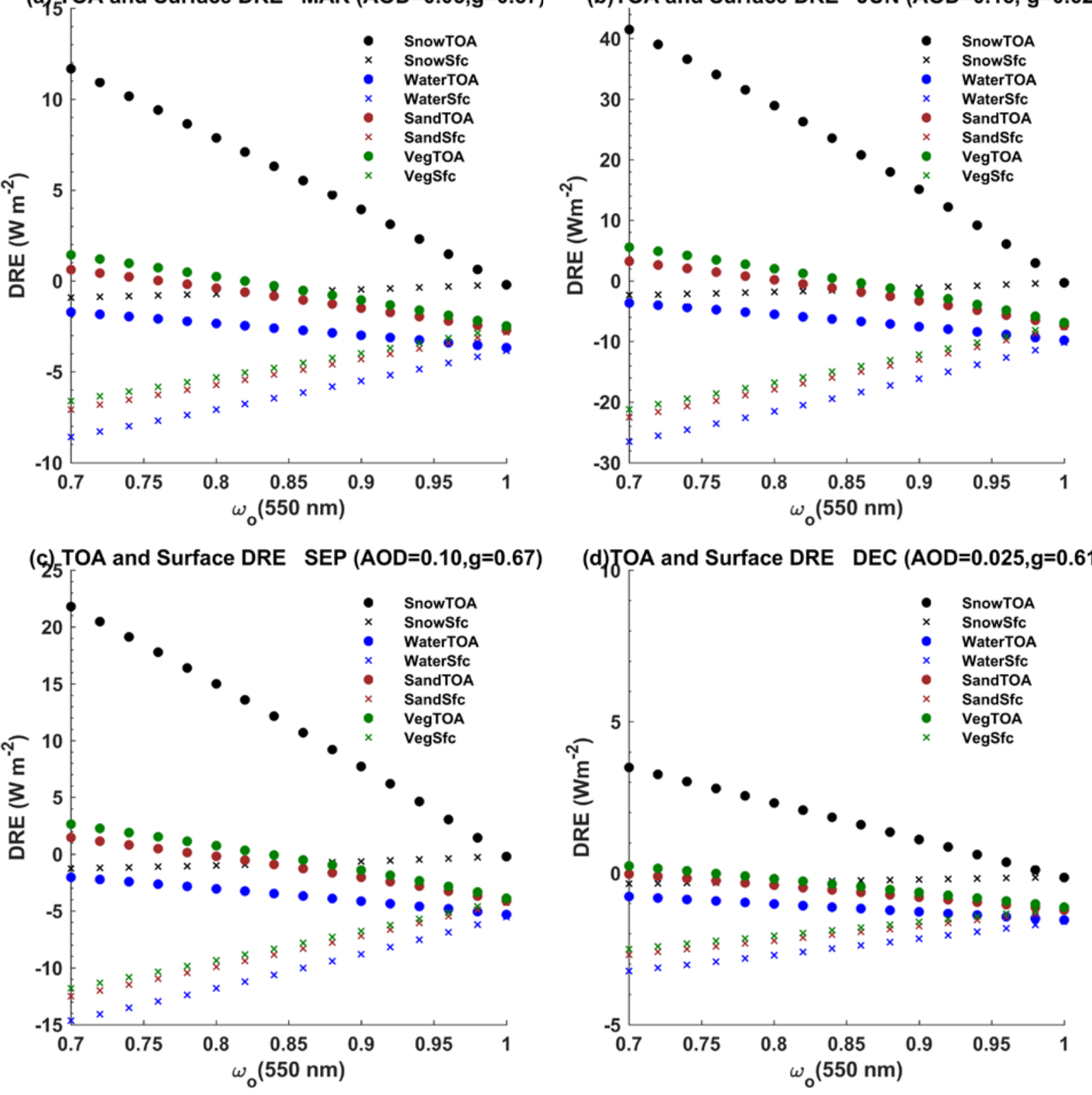

Fig. S4. Sensitivity of DRE at the TOA and surface to changes in $\omega_{0}$ for the following surface types: snow, seawater, sand, and vegetation; for MAR, JUN, SEP, and DEC. The base-case value of AOD and g for each season (Table 1 of paper) are included in each plot title. 